\title{
ALPHA V BETA 3 INTEGRIN EXPRESSION IN THE ENDOMETRIUM OF INFERTILE WOMEN WITH ENDOMETRIOSIS
}

\author{
Amal Z. Azzam, M.D.*, Nahla A. F. Kamel, M.D.** \\ Department of Obstetrics and Gynecology*, Department of Pathology**, \\ Faculty of Medicine, Alexandria Univesity
}

\section{ABSTRACI}

Objectives: To evaluate the expression of Alpha $V$ Beta 3 integrin $(\alpha V \beta 3)$ in infertile women with endometriosis in the midluteal in-phase endometrial biopsies.

Design: Prospective controlled study.

Setting: Department of Ubstetrics and Gynaecology. Shatby University Hospital and Department of Pathology, Alexandria University.

Subjects: Twenty five infertile females having stage I or II endometriosis (group I) and twenty fertile controls (group II).

Interventions: Midluteal endometrial biopsies by suction pipette were carried out during the implantation window. Immunohistochemical staining for the expression of $\alpha \mathrm{V} \beta 3$ integrins and progesterone receptors (PR) in endometrial samples were performed. Serum levels of estradiol and progesterone were measured at the same day of endometrial biopsy.

Main outcome measures: $\alpha \mathrm{V} \beta 3$ integrin was significantly reduced ( $\mathrm{p}=0.001$ ) in infertile patients with endometriosis (44\%) compared to fertile controls $(80 \%)$. Patients in group (I) had a statistically significant reduction ( $\mathrm{p}=0.001$ ) in the overall mean intensity score compared to women in group (II) $(0.52 \pm 0.65 \mathrm{vs} 2.0 \pm 1.21)$. The expression of oV $\beta 3$ was mainly glandular in both groups. However, in patients with positive integrin expression. the percentage of glandulat expression as well as the mean intensity score was significantly reduced in group (I) compared to group (II) ( $p=0.001$, $p=0.0001$ respectively). Hormonal levels were comparable between groups. The epithelial PRs were down regulated in all in-phase endometrial samples in both groups. Integrin expression was inversely correlated with epithelial PRs in the control group $(r=-0.89, p=0.001)$ but no correlation was found in the endometriosis group $(r=0.14, p=0.39)$.

Conclusion: $\alpha V \beta 3$ integrin expression is reduced during the window of implantation in infertile patients with stage I or II endometriosis denoting that defective uterine receptivity might be an unrecognized cause of associdated infertility in those women.

Keywords: $\alpha$ VB3 integrin, endometriosis, endometrial biopsy, window of implantation, progesterone receptors.

\section{INTRODUCTION}

As a normal endometrial milieu is essential for implantation, evaluation of endometrial receptivity (the period during which successful implantation can occur) has been considered a basic goal in the assessment of infertile women (1)
It is now generally accepted that the endometrium is receptive to blastocyst implantation only during a short period in the luteal phase known as the implantation window which is estimated to lall beiween postovulatory days 6-10 based on early histologic studies and the use of highly sensitive HCG sudies (2.3) Several molecular markers have 
been shown to appear in the endometrial mucosa during this period suggesting that they may be involved in receptivity ${ }^{(4)}$.

Integrins comprise a large family of cation-dependant heterodimeric transmembrane receptors composed of non-covalently linked $\alpha$ and $\beta$ subunits. The major function of integrins is to mediate cell-to-cell and cell-to-substrate attachments although they also modulate a number of other cellular functions ${ }^{(5,6)}$. The expression of one specific integrin $\alpha V \beta 3$ on the epithelial lining of the uterus frames the putative window of implantation (7) and makes this integrin of unique importance in the assessment of endometrial receptivity (8) and increases the chances of successful implantation among infertile women especially those with endometriosis ${ }^{(9)}$.

It has been indicated that an abnormal pattern of expression of $\beta 3$ integrin subunits may be associated with states of impaired fertility, Even morphologically normal (in-phase) endometrium may be functionally abnormal. These observations have led to the proposal for the evaluation of $\alpha V \beta 3$ integrin expression in combination with histologic dating in the determination of an endometrial cause of a patient's infertility $(8,10-12)$.

Endometriosis is one of the most prevalent diseases in gynecology affecting about $15 \%$ of women of child bearing age. It is an estrogen-correlated benign disease characterized by a marked ability of endometrial-like cells to invade and proliferate outside uterine cavity (13). To this day, despite a plethora of scientific information and clinical observations, the etiology of endometriosis remains unresolved, it's pathology disputed and its treatment inadequate.

A significant association betwen minimal and mild endometriosis, and infertility is shown by prevalence studies (14). However, the exact mechanism by which endometriosis affects infertility is still unknown (15). Virtually, every step in reproduction has been investigated and purposed to be impaired in the presence of endometriosis. At present, controversy exists as to whether reduced implantation in patients with endometriosis is due to hampered oocyte/ embryo quality or endomerial inadequacy (16).

The objective of this study" was to evaluate the expression of Alpha $\mathrm{V}$ Beta 3 integrin in infertile women with endometriosis. A better understanding of defects in uterine receptivity may lead to a more directed therapeutic approach to such patients and remove some of the uncertainty that surrounds the diagnosis,

\section{PATIENTS\& METHODS}

In this prospective controlled study, we investigated the expression of $\alpha V \beta 3$ integrin in the endometrium of 45 women attending the out-patient clinic of sShatby University Hospital. They were divided into two groups: Group (I) included 25 infertile patients undergoing a routine work up and being diagnosed laparoscopically as having stage I or II endometriosis, according to the American Fertility Society (AFS) Score, (17) as their sole cause of infertility or admitted diagnosed as endometriosis from the start, and group (II) included 20 fertile healthy women and served as controls. All women were informed about the procedures and an informed consent was obtained.

The inclusion criteria of patients in group (I) included normal ovulation determined by serial ultrasonographic scans, midluteal progesterone levels and in-phase endometrial samples, while the includsion criteria of patients in group (II) were: being healthy, with proven fertility (the presence of at least one term pregnancy or past delivery) and had a regular menstrual cycle. The exclusion criteria of 
both groups were out of phase endometrium, history of undizgnosed vaginal blecding. any form of homone replacement thesipy or other alternatives for at least the last six months and present or past history of genial malignancy.

All cases were subjected to thorough and comprehensive medical history and clinical examination with an emphasis on local gynecological examination including per vaginal and speculum examinations.

\section{Endometrial biopsy:}

All endometrial biopsies were obtained from the uterine fundus collected through a standard endometrial biopsy technique. The samples were taken as an office procedure (without any anesthesia or analgesia) by suction curettage using an endometral suction pipette (Select cells(B) on postovulatory day $6-8$.

Commencing on days $8-10$ of the study cycle (depending on the cycle length of the women) padenes underwent daily transvaginal ultrasonographic evaluation of the follicular growth using a $5 \mathrm{MHZ}$ vaginal transducer attached to FUKUDA-UF 810 XTD scanner (Japan). Both ovaries were identified and the largest diameter was measured in both longitudinal and transverse dimensions in all follicles. the day of ovulation was designanted as the day of maximum follicular enlargement followed the nexi day by sudden disappearance or filling in of this follicle showing loss of clear demarcation of its walls and intrafollicular echoes, in association with the presence of free fluids in the Douglas pouch.

Endometrial biopsies were fixed in 10\% Cormalin and embedded in paraffin for light microscopy and immunohistochemistry. Factors that affect interpretaiton of the test results are the cycle day of the specimen collection. the collection technique and the length of time the specimen sits in formalin (18).
One observer, an expert pathologist who was blinded as regards to patient identification and the ultmsonographically detected ovulatory day. performed all of the assessments including endometrial dating and immunohistochemistry.

\section{Endometrial dating:}

Paraffin blocks were sechoned (4 um sections) and stained with hematoxylin and eosin. All the endometrial biopsies were dated according to histopathological criteria of Noyes et al (19) to cxclude out of phase endometrium which was defined as $\geq 3$ days lag between the chronological and histological day ${ }^{(2)}$.

\section{Immunohistochemistry:}

Chosen sections were mounted on coated slides for immunohistochemical staining using $\alpha V \beta 3$ integrin and progesterone receptors (PR) using streptavidin-biotin complex technique.

\section{a- aV $\beta 3$ integrin :}

Immunohistochemical staining was pertormed using Mouse monoclonal antibody CD61 (GPIIa) (Novocastra laboratories. Newcastle, UK), ready for use.

\section{b- Progesterone receptors (PR):}

Immunohistochemical staining was performed using Rabbit monoclonal antibody, progesteron receptors (Neomarkers, labvision, Clone Sp2 Fermont CA. USA) diluted 1:200 with phosphati buffered saline.

The intensity of staining of endometriat components was evaluated by a serniquantitative scoring system as follows: absent (o), weak or focal $(+)$. moderate $(++)$ and strong $(+++)^{(2 l)}$. Endometrial samples were considered as expressing $\alpha$ VB3 integrin when there is brown cytoplasmic staining using DAB chromagen in endometrial glands or luminal surface epithelium with any intensity of the reaction runging from focalweak to strong. Progesterone receptor 
positive staining was detected as brown ruclear staining using DAB chromagen as counter stain.

\section{Hormonal assays:}

Venous blood was withdrawn for hormonal measurements on the same day as endometrial sampling after overnight fasting blood was allowed to clot and serum was separated and stored at $-20^{\circ} \mathrm{C}$ until assayed using commercially available kits. Estradiol was measured by a competitive immuno-enzymatic assay (Immuno I; Bayer, Tarry Town, NY, USA). The sensitivity of the assay was 10 $\mathrm{pg} / \mathrm{ml}$ and the interassay coefficient of variation $5 \%$. Progesterone was measured by a competitive chemiluminiscent immunoassay (Immulite, DPC, Los Angeles, CA, USA). The sensitivity of the test was $0.2 \mathrm{ng} / \mathrm{ml}$ and the interassay coefficient of variation was $6.7 \%$

\section{Statistical analysis:}

Data were analysed by SPSS statistical software (Release 10.0, SPSS Inc., Chicago, II, USA). Student t-test and Mann-whitney U-test were used for comparison between continuous variables. $\chi^{2}$ test was used for categorical variables. The Pearson correlation coefficient was used for correlative analysis. Results were expressed as means \pm SD. The level of significance was set at $\mathrm{p} \leq 0.05$.

\section{RESULTS}

The age of all patients ranged from 20 to 38 years with a mean value of $29.24 \pm 5.83$ years in group (I) and $28.95 \pm 5.78$ years in group (II). All of them had regular menstrual cycles (27-32 days). The healthy control women had a mean parity of $1.85 \pm 0.88$ (range $1-3)$, (Table 1).

All menstrual cycles included in the present study were ovulatory according to ultrasonographic criteria and midluteal serum progesterone concentration $>10$ $\mathrm{ng} / \mathrm{ml}$. All samples were collected during the putative window of implantation (6-8 days postovulatory) from patients in whom the timing of biopsy was defined ultrasonographically and confirmed by histological criteria. (Fig.1)

There was no statistical significant difference (p>0.05) among the two groups as regards age, day of biopsy and histological data, table (1). Also, no statistical significant differences in midluteal serum concentrations of estradiol or progesterone were detected among patients of both groups $(\mathrm{p}>0.05)$, (Table II).

The overall $\alpha \mathrm{V} \beta 3$ integrin expression was detected in 27 out of $45(60 \%)$ of midluteal endometrial biopsies, (11 out of 25 in group I and 16 out of 20 in group II). The percentage of positive samples of $\alpha \vee \beta 3$ integrin expression was significantly higher $(\mathrm{p}=0.001)$ in the control group $(80 \%)$ than in the endometriosis group (44\%). Also, patients with endometriosis had a statistically significant reduction (p-0.001) in the overal mean intensity score compared with fertile controls $(0.52 \pm 0.65$ vs $2.0 \pm 1.2, p=0.001)$. Fourteen out of twenty five patients with endometriosis $(56 \%)$ and four of twenty fertile controls (20\%) had samples that were negative for aVB3 expression, (Table II, Fig 2,3)

The expression of $\alpha$ V $\beta 3$ was mainly glandular in both groups. In patients with positive integrin expression, the percentage of glandular expression was significanlty reduced in group I compared to group II $(63.6 \%$ vs $100 \%, \mathrm{p}=0.001)$. However, no statistical significant difference was detected in both groups as regards the percentage of luminal expression (45.5\% vs 56.3\%, $\mathrm{p}=0.42$ ), Tabel (III). Also, the mean intensity score was significantly decreased in glandular epithelium in patients of group I compared to those in group II $(0.8240 .75 \mathrm{vs}$ $2.44 \pm 0.89, p=0.0001$ ), (Table IV, Fig 2).

The epithelial progesterone receptors were down-regulated in all in-phase endometrial samples 
of both groups, (Fig 4). Multiple regression analysis revealed that integrin expression was inversely correlated with epithelial PRs in normal fertile controls, $(\mathrm{r}=0.89, \mathrm{p}=0.001)$, (Fig 5), while in endometriosis, it was not, $(\mathrm{r}=0.14, \mathrm{p}=0.39)$. Also, patients age was not correlated with abnormalities of integrin expression $(r=0.113, \quad p>0.05)$ or PRs $(\mathrm{r}=-0.132, \mathrm{p}>0.05)$.

Table I : Demographic characteristics of patients (endometriosis) and fertile controls undergoing endometrial biopsy during the midluteal phase.

\begin{tabular}{|l|c|c|c|c|}
\hline \multicolumn{1}{|c|}{ Characteristics } & $\begin{array}{c}\text { Group I } \\
(\mathbf{n = 2 5})\end{array}$ & $\begin{array}{c}\text { Group II } \\
(\mathbf{n}=\mathbf{2 0})\end{array}$ & $\mathbf{t}$ & $\mathbf{p}$ \\
\hline $\begin{array}{l}\text { Age (years) } \\
\text { Mean } \pm \text { SD } \\
\text { Range }\end{array}$ & $\begin{array}{c}29.24 \pm 5.83 \\
20-38\end{array}$ & $\begin{array}{c}28.95 \pm 5.78 \\
20-37\end{array}$ & 0.15 & 0.78 \\
\hline $\begin{array}{l}\text { Parity } \\
\text { Mean } \pm \text { SD } \\
\text { Range }\end{array}$ & - & $1.85 \pm 0.88$ & - & - \\
\hline $\begin{array}{l}\text { Day of biopsy (postovulatory) } \\
\text { Mean } \pm \text { SD } \\
\text { Range }\end{array}$ & $7.0 \pm 0.82$ & $7.05 \pm 0.83$ & 0.22 & 0.68 \\
\hline $\begin{array}{l}\text { Histological date } \\
\text { Mean } \pm \text { SD } \\
\text { Range }\end{array}$ & $6-8$ & $6-8$ & & \\
\hline
\end{tabular}

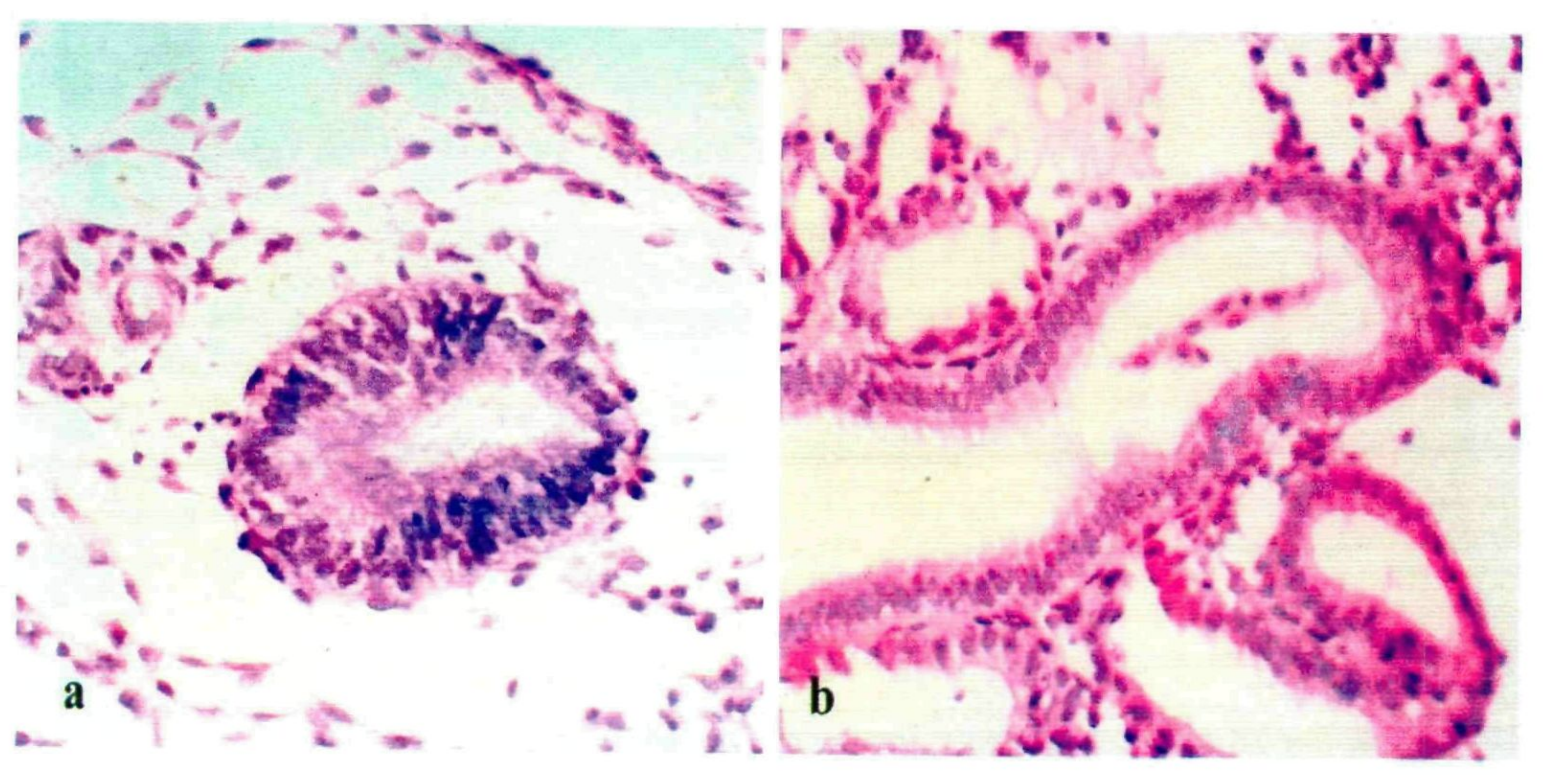

Fig. 1. : Endometrium at mid-luteal period (6-8 days postovulatory) showing marked stromal oedema, prominent glandular secretion (a), and ragged luminal border (b). [H\&E X 400(a,b)]. 

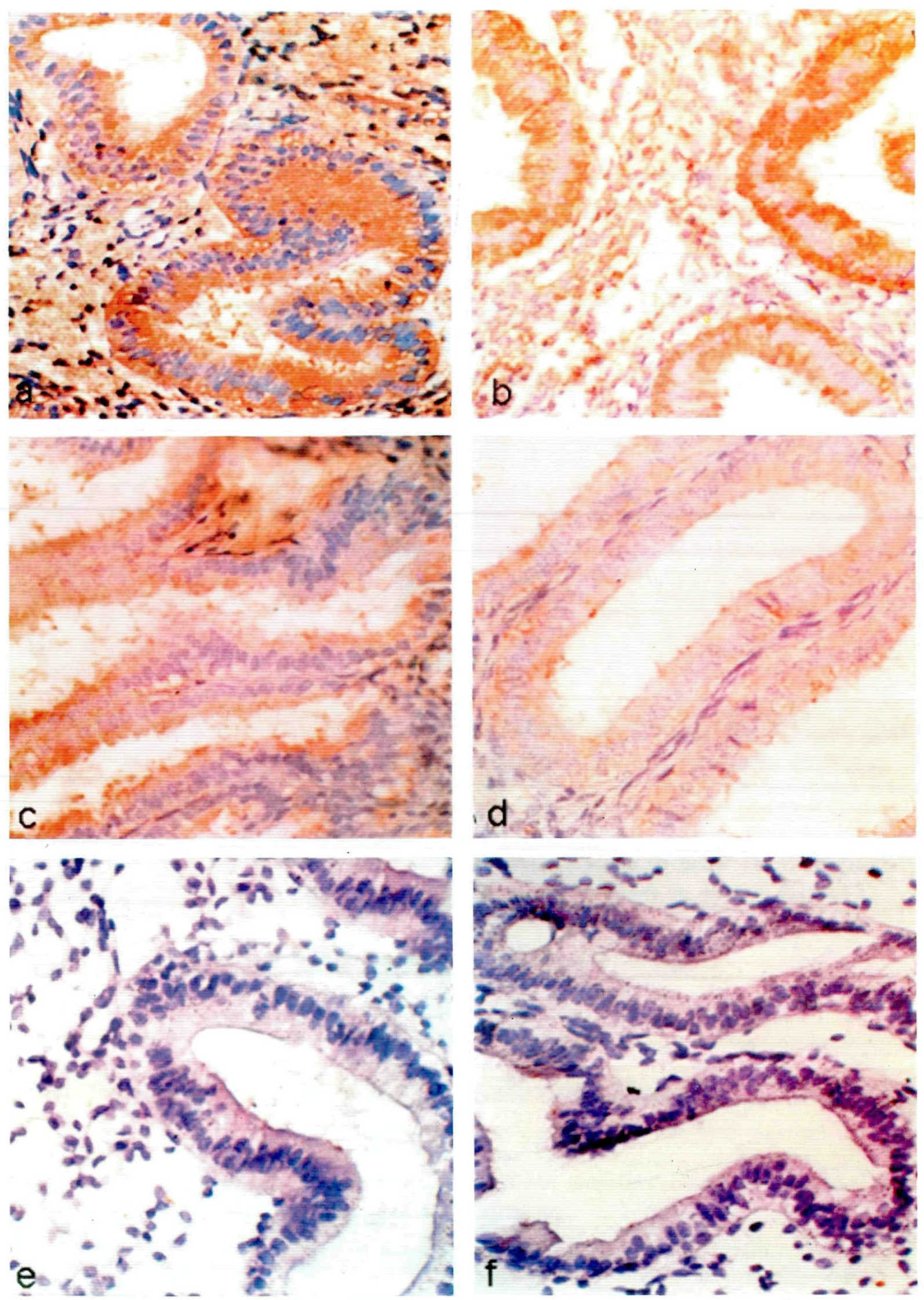

Fig. 2. : $\alpha V \alpha \beta 3$ integrin immunohistochemical staining : (a,b) strong brown cytoplasmic glandular staining, (c,d) weak sytoplasmic brown glandular staining, (e,f) negative immunohistochemical staining 
Table II : $\alpha$ V $\beta 3$ integrin expression and hormonal levels in both groups in the midluteal phase.

\begin{tabular}{|c|c|c|c|c|}
\hline Parameters & $\begin{array}{c}\text { Group I } \\
(\mathbf{n}=25)\end{array}$ & $\begin{array}{c}\text { Group II } \\
(\mathbf{n}=20)\end{array}$ & test & p \\
\hline I. $\alpha$ V $\beta 3$ integrin expression & & & $\mathrm{Z}=2.7$ & $0.001^{*}$ \\
a- Positive samples $\mathrm{n}(\%)$ & $11(44 \%)$ & $16(80 \%)$ & $\mathrm{t}=5.16$ & $0.001^{*}$ \\
b- Mean staining score & $0.52 \pm 0.65$ & $2.0 \pm 1.21$ & & 0.41 \\
\hline II- Hormonal concentrations: & & & $\mathrm{t}=0.41$ & 0.63 \\
a- Estradiol pg/ml & $150.1 \pm 15.16$ & $148.7 \pm 14.67$ & $\mathrm{t}=0.48$ & \\
b- Progesterone $\mathrm{ng} / \mathrm{ml}$ & $15.96 \pm 1.27$ & $16.15 \pm 1.37$ & & \\
\hline
\end{tabular}

* Significant at $p<0.05$

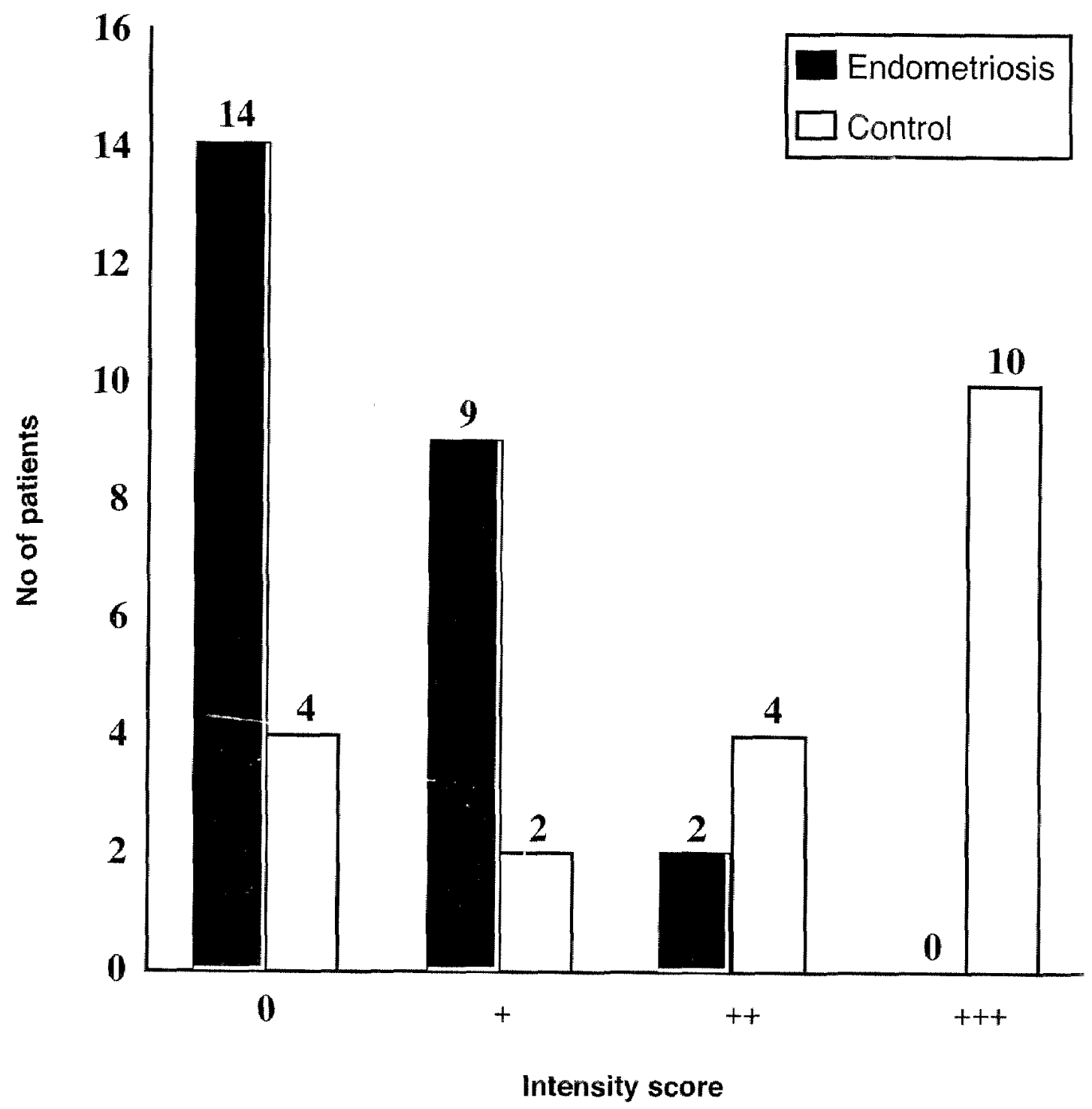

Fig. 3. : Distribution of endometrial specimens as regards staining intensity and $\alpha V \beta 3$ integrin exoression in both groups $[0=$ no staining $(-$ ve expression),,,++++++ indicate $\alpha$ VB3 expression]. 
Table III :Percentage of positive histochemical staining in patients with positive integrin expression in glandular and luminal epithelium in group I $(\mathbf{n}=11)$ and group II $(\mathbf{n}=16)$.

\begin{tabular}{|l|c|c|c|c|c|c|}
\hline \multirow{3}{*}{ Epithelium } & \multicolumn{4}{|c|}{ Positive histochemical staining } & \multirow{2}{*}{ Z } & \multirow{2}{*}{ P } \\
\cline { 2 - 5 } & \multicolumn{2}{|c|}{ Group I (n= 11) } & \multicolumn{2}{|c|}{ Group II (n= 16) } & & \\
\cline { 2 - 5 } & No & $\%$ & No & $\%$ & & \multirow{2}{*}{$0.001^{*}$} \\
\hline Glandular & 7 & 63.6 & 16 & $100 \%$ & 2.56 & 0.42 \\
\hline
\end{tabular}

* Significant at $\mathrm{p}<0.05$

Table IV :Mean intensity score in patients with positive integrin expression in glandular and luminal epithelium in both groups.

\begin{tabular}{|c|c|c|c|c|}
\hline \multirow[b]{2}{*}{ Epithelium } & \multicolumn{2}{|c|}{ Mean intensity score } & \multirow[b]{2}{*}{$t$} & \multirow[b]{2}{*}{$\mathbf{P}$} \\
\hline & Group I $(n=11)$ & Group II $(n=16)$ & & \\
\hline Glandular & $0.82 \pm 0.75$ & $2.44 \pm 0.89$ & 4.94 & $0.0001^{*}$ \\
\hline Luminal & $0.55 \pm 0.69$ & $1.19 \pm 1.22$ & 1.57 & 0.103 \\
\hline
\end{tabular}

Values are $\overline{\mathrm{X}} \pm \mathrm{SD}$.

* Significant at $\mathrm{p}<0.05$

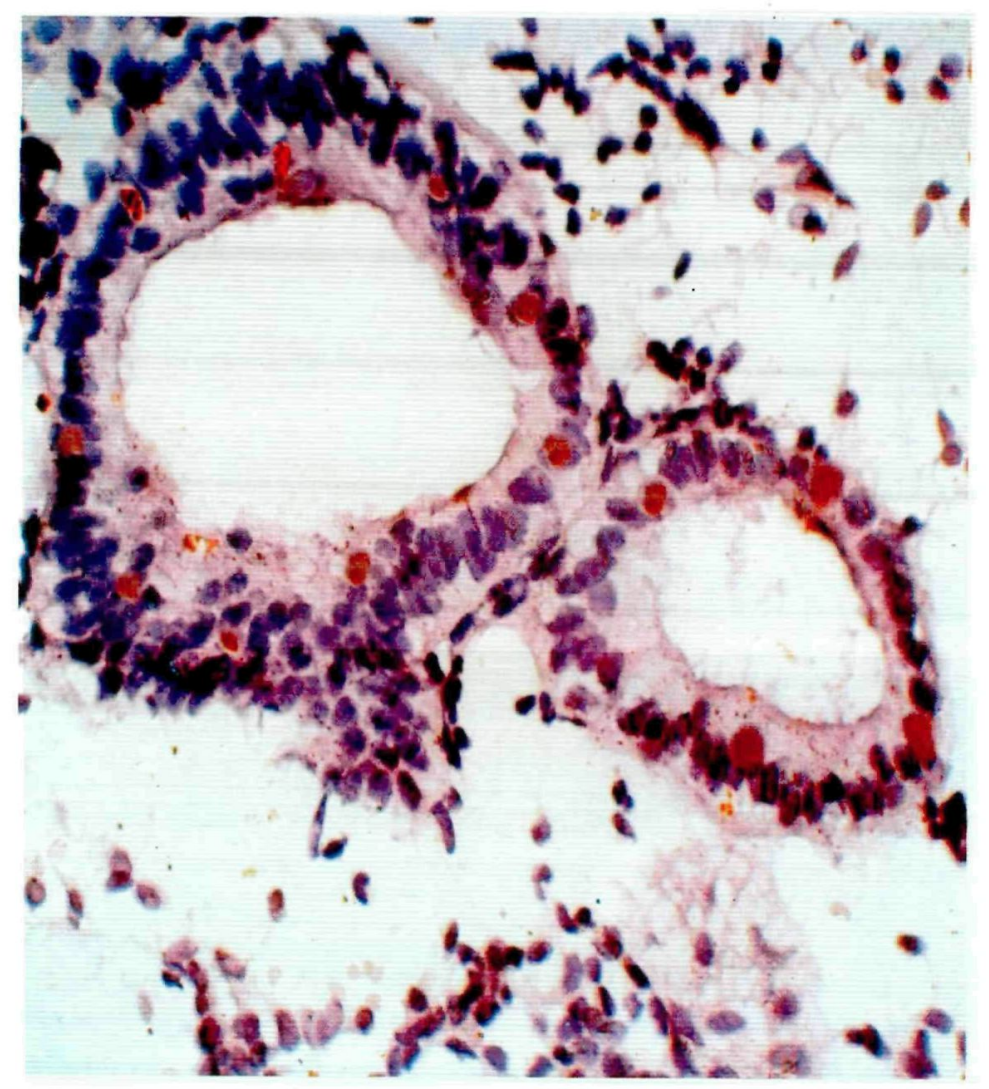

Fig. 4. : Progesteron receptor (PR) immunohistochemical staining showing focal weak brown nuclear glandular staining, indicating downregulation of PRs. 


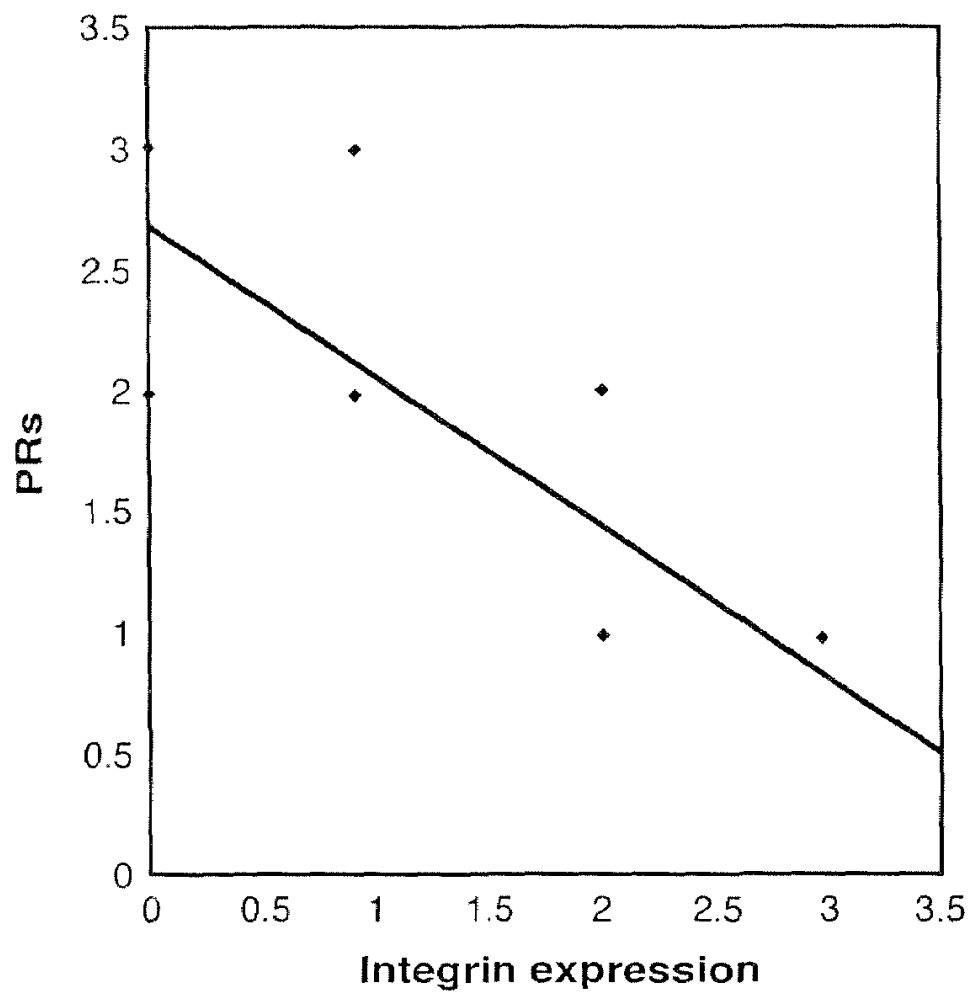

Fig. 5. Correlation betwen integrin expression and epithelial progesterone receptors in the control group.

\section{DISCUSSION}

Endometriosis is a disorder that affects approximately $2-5 \%$ of the general fertile population and its prevalence in infertile women is much higher and ranges from $20-40 \%$. No method other than laparoscopy has demonstrated value in the diagnosis of minimal or mild stage of the disease ${ }^{(22)}$. Few researchers have suggested that uterine receptivity might be adversely affected by the presence of endometriosis ${ }^{(23)}$.

For several decades, the most commonly used method to assess the endometrial function has been the endometrial biopsy and histological dating according to the criteria of Noyes et al ${ }^{(21)}$. However, the accuracy of morphological criteria to diagnose receptive and non receptive endometria is in question. Moreover, histological dating is a relatively crude and inferential measure of endometrial function ${ }^{(12)}$.
The limitaiton of histological dating has spurred investigators to seach for other potential markers of endometrial receptivity. Integrins are among the most extensively characterized markers with special reference to $\alpha$ V $\beta 3$ vitronectin receptor that first abruptly appears as the implantation window opens (cycle day 20) (21) and is inconspicuously absent in the endometrium of patients with certain types of infertility. (10) The use of such a marker with a binary result (positive or negative) as a test for endometrial receptivity rather than the complex dating criteria would improve significantly the evaluation of endometrial function (1).

In the present study, we used ultrasonographic monitoring of ovulation because previous studies have shown that the accuracy of histological dating is best determined when ovulation is detected by this $\operatorname{method}^{(24)}$ rather than period in infertile population ${ }^{(25)}$. Also, all the endometrial specimens were evaluated by the same pathologist. this avoiding 
interobserver and intraboserver variability in reading the same specimen the greatest source of errors in reading endometria) which might explain at least in part, the wide diversity of opinions in the literatures regarding the reliability of dating luteal endometrium (26)

In the present study, the reduction in $\alpha$ V $\beta 3$ integrin expression in women with mild or minimal endometriosis despite otherwise normal and timely histological development compared to controls might denote defective endometrial receptivity and would explain the reduced implantation in those patients. In agreement, Lessey et al (12) reported that endometriosis was positively correlated with reduced B3 integrin subunit expression. Also, Garacia-Velasco and Arici ${ }^{27}$ ) showed that eutopic endometrium of women with endometriosis behaves different from the endometrium of women without the disease. Again, Lessey ef al (11) found reduced endometrial $\alpha V \beta 3$ expression in nulliparous women with documented mild endometriosis. The same was also observed by others. $(8,10,28,29)$.

The association between $\alpha \mathrm{V} \beta 3$ integrin expression in the endometrium and AFS stage I or II endometriosis is interesting. Although the regulatory signal for the induction of endometrial $\alpha V \beta 3$ on day (19-20) is not yet known, it is tempting to speculate that bioactive secretions by such endometriotic implants or by activated macrophages may adversely affect the paracrine milieu (11). These substances could presumably gain access to the endometrium via vascular or tubal transport. Candidates include transforming growth factor- $\beta$, (3) which has been shown to regulate $\alpha V \beta 3$ (31) and interleukin-B receptor antagonists, reportedly elevated in women with minimal and mild endometriosis and demonstrated to interfere with implantation in a rodent model. (32) Another mechanism is the assumption that an increase in local estrogen production in endometriosis may account for decreased expression of $\alpha \mathrm{V} \beta 3$ integrin as estrogen has been shown 10 inhibit the expression of this integrin in the endometrium ${ }^{(33,34)}$. A third mechanism is the hormonal treatment available for the treatment of endometriosis and its symptoms which might have an effect on integrin expression (35).

Defects of uterine receptivity have received little attention in previous studies aimed at defining the pathophysiology of infertility associated with endometriosis. It has been postulated that a lack of timely $\alpha V \beta 3$ expression has been used to define two distinct types of defects of endometrial receptivity (11). Endometrium in which histological developmenmt is delayed or out of phase (as occurs in luteal phase defect) would uniformly fail to express $\alpha$ V $\beta 3$ integrin when glandular maturation has not progressed to at least cycle day 20 , a condition which was termed type I defect ${ }^{(8)}$. On contrast, type II defect would be one in which $\alpha$ V 33 expression is lacking in the normal in-phase endometrium which has been observed in a significant proportion of infertile women with mild or minimal endometriosis (11) and in those with unexplained infertility (8). However, the existence of type II defect was doubted by some authors as women having negative expression of $\alpha \vee \beta 3$ during the window of implantation expressed it 4 days later at the time of late biopsy $(21,36)$.

On the contrary, Ordi et al (37) found no significant differences in $\alpha$ V $\beta 3$ integrin expression between patients having stae I or II endometriosis associated infertility, unexplained infertility and fertile controls and attributed this to nomal endometrial receptivity in the studied groups or impaired oocyte/embryo quality leading to decrease in the implantation rate ${ }^{(15)}$. Others have reported that the association between minimal or mild endometriosis and infertility is far from conclusive and no treatmen appears to be as effective as treatment $(38,39)$. Also, $50 \%$ of women with 
endometriosis associated infertility would become pregnant without any tcatment ${ }^{(33)}$. Again, no differences in integrin expression between patients with or without endometriosis were reported by others $(20,21,40-42)$.

In the present study, although the expression of $\alpha V \beta 3$ was mainly glandular, yet it was reduced significantly in pationts with endometriosis compared with controls; the same was also found in the mean intensity score of the positive samples and this was in agreement with previous reports $(11,12,33)$. It has been reported recently that the compartmental rather than bulk expression of $\alpha$ V $\beta 3$ integrin in the endometrium might be more important when evaluating endometrial receptivity ${ }^{(43)}$. On the contrary, Creus et $\mathrm{al}^{(20)}$ reported no difference in the glandular expression of $\alpha V \beta 3$ integrin between normal control and endometriotic women and that $\alpha V \beta 3$ was present in endometrial glands and luminal endometrium in midluteal in-phase and out-phase endometria. Hii and Rogers ${ }^{(36)}$ reported that $\alpha V \beta 3$ integrin was present in the glandular epithelium throughout the cycle and was unaffected by endometriosis. Others have reported that $\alpha V \beta 3$ integrin appearing on the luminal and glandular epithelium only during the proliferative phase $^{(44)}$.

The discrepancies between studies might be attributed to loss of synchronous expression of $\alpha \mathrm{V} \beta 3$ integrin between glandular and stromal components of the endometrium ${ }^{(43)}$, difference in immunostaining by using different antibodies to $\alpha V \beta 3$ integrins ${ }^{(4,36)}$, or that the ligand binding may alter the confirmation of some integrins leading to inhibition of binding of some antibodies (45).

It seems clear that many of the physiological events that are crucial to successful implantation are driven by cyclic changes in the ovarian steroid hormonal milieu and that functional maturation of the endometrium is mediated by specific receptor proteins for estrogen (ER) and progesterone (PR). Cellular expression of these receptors is highly regulated, stimulated first by the exponential rise in preovulatory estrogen and later suppressed by progesterone during the luteal phase. It has been suggested that rising progesterone concentration down-regulates $P R$ in luminal and glandular epithelium which may be a critical step in the cascade of molecular events that ultimately renders the endometrium receptive to embryo implantation ${ }^{(10)}$.

Previous sstudies have demonstrated that endometrial $\alpha V \beta 3$ integrin expression is modulated by steroid homones in vitro ${ }^{(34)}$ and in vivo $(7,10,46)$ Effective regulation of endometrial steroid receptors may trigger expression of implantation-specific proteins (e.g. integrins) ${ }^{47}$. However, when this mechanism becomes ineffective, (i.e. insufficient loss of PR or high estrogen level at the time of implantation) abnormal expression of $\alpha \mathrm{V} \beta 3$ may occur $^{(43)}$.

In this study, in endometriosis group. endometrial dating was in phase and epithelial PRs were suppressed i.e. down regulated, also, steroid concentrations were nearly similar in both groups on days of endometrial samplings but $\alpha V \beta 3$ integrin in expression was nontheless decreased or absent suggesting that endometrial receptivity may develop for reasons other than inadequate progesterone production. It has been suggested that the expression of $\alpha V \beta 3$ although appears linked to down regulation of epithelial PRs, is subject to be regulated by other factors $(48,49)$ that may be present in abnormal quantities and/or unique forms in endometriosis (10.21). This would explain the lack of correlation between integrin expression and immunohistochemical analysis for PRs in group I.

The significant inverse correlation betwen integrin expression and epithelial PRs in the control group was on the contrary to Lessey et al (10) who 
demonstrated that although down-regulation of epithelial PRs might be expected when morphological development proceeds normally, if does not guarantee timely expression of $\alpha \mathrm{V} \beta 3$. Also, Vander-Linden et al ${ }^{(50)}$ found no relation between the expression of integrins and the expression of estrogen and progesterone receptors in normal human endometrium throughout the menstrual cycle.

In conclusion, the present study indicates that in women with mild or minimal endometriosis, integrin expression is reduced in mildluteal in-phase endoemtrial biopsies denoting defective uterine receptivity and may provide further insight into the pathophysiology of this disease. Large studies of adequate statistical power are warranted to establish the usefulness of these markers as clinical diagnostic tools in infertility and as a novel approach to contraception,

\section{REFERENCES}

I. Ordi J, Creus M, Ferrer B, Fabregues F, Carmona F, Casamitjana R, Vanrell JA, Balasch J. Midluteal endometrial bipsy and $\alpha \mathrm{V} \beta 3$ integrin expression in the evaluation of the endometrium in infertility. Implications for fecundity. In J Gynecol Pathol $2002 ; 21(3): 231-238$.

2. Bergh PA, Navot D. The impact of embryonic development and endometrial maturity on the timing of implantation. Fertil Steril 1992; 58: 537-542.

3. Wilcox AJ, Baird DD, Weinberg CR. Time of implantation of the conceptus and loss of preganncy. N Eng J Med 1999; 340: 1796-1799.

4. Lessay BA. The use of integrin for the assessment of uterine receptivity. Fertil Steril 1994; 61: 812-814.

5. Hynes RO. Integrins: Versatility, modulation and signalign in cell adhesion. Cell 1992; 69: / I-25.

6. Kim LT, Yamada KM. The regulation of expression of integrin receptors. Proc Soc Exp Biol Med 1997; 214: $123-131$

7. Lessey BA, Castelbaum AJ, Buck CA, Lei Y, Yowell CW, Sun J. Further characterization of endometrial integrins during the menstrual cycle and in pregnancy. Fertil Steril 1994; 62: 497-506.

8. Lessey BA, Castelbaum AJ, Sawin SW, Sun J Integrins as markers of uterine receptivity in women with primary unexplained infertility. Festil steril $1995 ; 63: 535-542$.

9. Lessey BA, Castelbaun AJ, Harris J, Sun J, Young SL, Wolf L. Lmprovement in pregnancy rates with GnRH agonist in women with infertility, minimal or mild endometriosis and aberrant $\alpha V \beta 3$ expression Am Soc Reprod Med Annual Mtg 1996;0165: 582.

10. Lessey BA, Yeh I, Castelbaum AJ, et al. Endometrial progesterone receptors and markers of uterine receptivity in the window of imptantation. Fertil Steril 1996: 65: 477-483.

11. Lessey BA, Castelbaum AJ, Sawin SJ, Buck CA. Schinnar R, Wikins B, Strom BL. aberrant integrin expression in the endometrium of women with endometriosis. J Clin Endocrinol Metab 1994; 79: $643-649$

12. Lessey BA. Castelbaum AJ, Wolf L, Green $W$, Paulson M. Mcyer WR, Fritz MA. Use of integrins to date the endometrium. Fertil Steril 2000; 73: $779-787$.

13. Hemmings R, Rivard M, Olive D, Poliguin J, Fleury D, geagne D. Hugo P, Gosselin D. Evaluation of risk factors associated with endometriosis. Fertil Steril 2004; 81: 1513-1521.

14. Trinder J, Cabill DJ. Endometriosis an infertility. The debate continues. Hum Fertil 2002; 5: 521 -527.

15. Mahute NG, Arici A. Endometriosis and assisted reproductive technologies: are outcomes affected? Curr Opin Obstel Gynecol 2001: 13:275-279. 
16. Garrido N, Navarro J, Simon C. The endometrium versus embryonic quality in endometriosis-related infertility. Hum Reprod Update 2002; 8: 95-103.

17. American Fertility Society. Revised American Fertility Society classification of endometriosis. Fertil Steril 1985; 42: 351-352.

18. Ordi J. Creus M, Quinto L. Casamitjana R, Cardesa A, Balasch J. Within subject betwen-cycle variability of histological dating, $\alpha V \beta 3$ integrin expression and pinpod formation in the human endometrium. J Clin Endocrinol Metab 2003; 88(5): 2119-2125.

19. Noyes RW, Herting AT, Rock J. Dating the endometrial biopsy. Fertil Steil 1950; 1: 3-25.

20. Creus M, Ordi J, Fabregues F, Casamitjana R, Ferrer $B$, Coli E, Vanrell JA, Balasch J. $\alpha V \beta 3$ integrin expression and pinopod formation in normal and out-of-phase-endometria of fertile and infertile women. Hum Reprod 2002; 17(9): 2279-2286

21. Creus $M$, Balasch $J$, Ordi $J$, Fabragues $F$, Casamitjana R, Qumto L, Coutifaris C, Vancell JA. Integrin expression in normal and out-of-phase endometria. Hum reprod 1998; 13: 3460-3468.

22. Strathy JH, Moigaard CA, Coulam CB, Melton LJ. Endometriosis and infertility: a laparoscopic study of endometriosis among fertile and infertile women. Fertil Steril 1982; 38: 667-675.

23. Hahn DW, Carraher RP, Foldesy RC, McGuise JL. Experimental evidence for failure to implant as a mechanism of infertility associated with endometriosis. Am J Obstet Gynecol 1986; 155: $1109-1113$.

24. Shoupe D, Mishell DR, Lacarra M, Lobo RA. Horenstein I, D'Ablaing G, Moyer D. Correlation of endometrial maturation with four methods of estimating day of ovulation. Obstet Gynecol 1989; 73: $88-92$.

25. Li TC, Cooke ID. Evaluation of the luteal phase. Hum Reprod 1991; 6: 484-499.
26. Duggan MA. Brasher P. Oster A, Scurry. Kneafsey P. difrancesco 1. The accuracy and interobserver reproducibility of endometrial dating. Pathology $2001 ; 33: 392-397$.

27. garcia-Velasco JA, Arici A. Is the endometrium or oocyte/embryo affected in endometriosis: Hum Reprod 1999: 14: 77-89.

28. Lessey BA. Implantation defects in infertile women with endometriosis. Ann N Y Acad Sci 2002; 955 : 265-280.

29. Fedele L, Marchini M, Bianchi S, Dorta M, Arcaini L, Fontana PE. Structural and ultrastuctural defects in preovulatory endometrium of normo-ovulating infertile women with minimal or mild endometriosis. Fertil Steril 1990; 53: 989-993.

30. Oosterlynck DJ, Meuleman C, Wate M, Koninckx PR. Transforming growth factor- $\beta$ activity is increased in peritoneal fluid from women with endometriosis Obstet Gynecol 1994: 83: 287-292.

31. Ignotz RA, Heino J, Massague J. Regulation of cell adhesion receptors by transforming growth factor-beta. Regulation of vitronectin receptor and LFA-1. J Biol Chem 1989; 264: 389-392.

32. Simon C, Frances A, Piquette GN, et al. Embryonic implantarion in mice is blocked by interleukin-1 receptor antagonist. Endocrinology 1994; 134 : $521-528$.

33. Khorram O. Lessey BA. Alteration in the expression of endometral endothelial nitrie oxide synthase and $\alpha V \beta 3$ integrin in women with endometriosis. Fertile Steril 2002; 78(4):860--864.

34. Somkuti SG, Yuan LW. Fritz MA, Lessey BA. Epidermal growth factor and sex steroids dynamically regulate a marker of endometrial receptivity in Ishikaa cells. J Clin Endocrinol Metab 1997; 82: 2192-2197. 
35. Seibel MM, Berger MJ, Weinstein FG, Taymur ML.

The effectiveness of danazol on subsequent fertility in minimal endometriosis. Fertil Steril 1982; 38: $534-537$.

36. Hii LL, Rogers PA. Endometrial vascular and glandular expression of integrin alpha (V) beta (3) in women with and without endometriosis. Hum Reprod 1998; 13: 1030-1035.

37. Ordi J, Creus $M$, Casamitjana $R$, Cardesa A, Vanrell $J A$, Balasch J. Endometrial pinpode and $\alpha V \beta 3$ integrin expression is not impaire in infertile patients with endometriosis. Journal of Assisted Reproduction and Genetics $2003 ; 20(11)$ : 465-473.

38. Hughes EG, Ferdorkow DM, Collins JA. A quantitative overview of controlled trials in endometriosis associated infertility. Fertil Steril 1993; 59: 963-967.

39. Farquhar C, Sutton C. the evidence for the management of endometriosis. Curr Opin Obstet Gynecol 1998; 10: 321-332.

40. Berubê S, Marcoux S, Langevin M, Maheux R. The Canadian Collaborative Group on endometriosis. Fertil Steril 1998: 69: 1034-1041.

41. Thomas K, Thomson AJ, Wood SJ, Kingsland CR, Vince G, Lewis- Jones DI. Endometrial integrin expression in women undergoing IVF and ICSI: a comparison of the two groups and Fertile controls. Hum Reprod 2003; 18(2): 364-369.

42. Gaetje R, Rody A, Kissier S, Kaufmann M, Ahr A. Integrin expression $n$ eutopic and ectopic endometrium . zentrablbl Gynakol 2006; 128(3): 135-137.

43. Ceydeli N, Kaleli S, Calay Z, Erel CT, Akbas F, Ertungealp E. Difference in $\alpha \mathrm{V} \beta 3$ integrin expression in endometrial stromal cell in subgroups of women with unexplained infertility. European Journal of Obstetrics \& gynecology and Reproductive Biology 2006; 126: 206-211.

44. Bridges JOE, Prentice A, Roche W, et al. Expression of integrin adhesion molecules in endometrium and endometriosis. $\mathrm{Br} J$ Obstet Gynecol 1994; 101: 696-700.

45. Honda S, tomiyama Y, Pelletier AJ, topography of ligannd-induced binding sites, including a noveo cation-sensitive epitope (APs) at the amino-terminus, of the human integrin $\beta 3$ subunit $J$ Biol Chem 1995; 270: 11947-11954.

46. Sueoka K, Shiokawa S, Miyazaki T, Kuji N, Tanaka M, Yoshimura $Y_{.}$, Integrins and reproductive physiology: expression and modulation in fertilization, embryogenesis and implantation . Fertil Steril 1997; 67: 799-811.

47. Lessey BA, Arnold JT. Paracrine signaling in the endometrium: integrins and the establishment of uterine receptivity. J Reprod Immunol 1998; 39 : $105-116$.

48. Lessey BA. Endometrial integrins and establishment of uterine receptivity. Hum Reprod 1998; 13 247-258.

49. Grosskinsky CM, Yowell CW, Sun J, et al. Modulation of integrin expression in endometrial stromal cells in vitro. J Clin Endocrinol Metab 1996; 81: $2047-2054$.

50. Vander-linden PJO, De-Goeij AFPM, Dunselman GAJ, et al. Expression of cadhrins and integrins in human endometrium throughout the menstrual cycle. Fertil Steril 1995; 63: 1210-1216. 